\title{
Suicide and Lyme and associated diseases
}

\section{Robert C Bransfield}

Department of Psychiatry, Rutgers-RWJ Medical School, Piscataway, NJ, USA

\section{Video abstract}

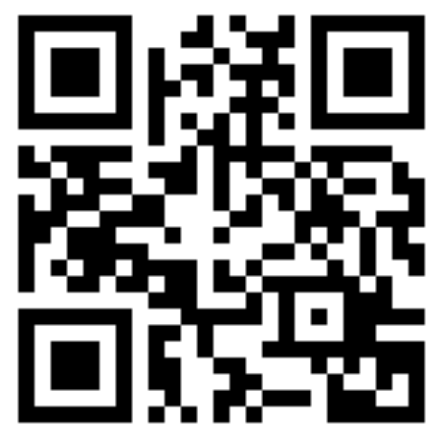

Point your SmartPhone at the code above. If you have a QR code reader the video abstract will appear. Or use: http://youtu.be/hyHgVIOdBOg

Correspondence: Robert C Bransfield 225 Highway 35, Suite 107, Red Bank, NJ 0770I, USA

$\mathrm{Tel}+\mathrm{I} 73274 \mid 3263$

Fax + I $73274 \mid 5308$

Email bransfield@comcast.net
This article was published in the following Dove Press journal:

Neuropsychiatric Disease and Treatment

16 June 2017

Number of times this article has been viewed

Purpose: The aim of this paper is to investigate the association between suicide and Lyme and associated diseases (LAD). No journal article has previously performed a comprehensive assessment of this subject.

Introduction: Multiple case reports and other references demonstrate a causal association between suicidal risk and LAD. Suicide risk is greater in outdoor workers and veterans, both with greater LAD exposure. Multiple studies demonstrate many infections and the associated proinflammatory cytokines, inflammatory-mediated metabolic changes, and quinolinic acid and glutamate changes alter neural circuits which increase suicidality. A similar pathophysiology occurs in LAD.

Method: A retrospective chart review and epidemiological calculations were performed.

Results: LAD contributed to suicidality, and sometimes homicidality, in individuals who were not suicidal before infection. A higher level of risk to self and others is associated with multiple symptoms developing after acquiring $\mathrm{LAD}$, in particular, explosive anger, intrusive images, sudden mood swings, paranoia, dissociative episodes, hallucinations, disinhibition, panic disorder, rapid cycling bipolar, depersonalization, social anxiety disorder, substance abuse, hypervigilance, generalized anxiety disorder, genital-urinary symptoms, chronic pain, anhedonia, depression, low frustration tolerance, and posttraumatic stress disorder. Negative attitudes about LAD from family, friends, doctors, and the health care system may also contribute to suicide risk. By indirect calculations, it is estimated there are possibly over 1,200 LAD suicides in the US per year.

Conclusion: Suicidality seen in LAD contributes to causing a significant number of previously unexplained suicides and is associated with immune-mediated and metabolic changes resulting in psychiatric and other symptoms which are possibly intensified by negative attitudes about LAD from others. Some LAD suicides are associated with being overwhelmed by multiple debilitating symptoms, and others are impulsive, bizarre, and unpredictable. Greater understanding and a direct method of acquiring LAD suicide statistics is needed. It is suggested that medical examiners, the Centers for Disease Control and Prevention, and other epidemiological organizations proactively evaluate the association between LAD and suicide.

Keywords: depression, tick-borne, immune, homicidal, epidemiology, psychoimmunology

\section{Plain language summary}

Currently, there are over 40,000 well-documented and many more undocumented suicides in the US each year, and many are unexplained. A number of infectious diseases, and in particular chronic infectious diseases, have also been associated with suicide. This article analyzes the association between suicide and Lyme and associated diseases (LAD). Based upon the medical literature demonstrating the physiology associated with suicide, a chart review, and epidemiological calculations, it was demonstrated there is a causal relationship between LAD and suicide, and the pathophysiology of LAD can be explained and it causes a significant number of suicides. LAD causes immune effects, biochemical changes, and a number of psychiatric symptoms that contribute to suicidal risk. By indirect calculations, it is estimated there are possibly over 
1,200 LAD suicides in the US per year. Greater understanding and a direct method of acquiring LAD suicide statistics is needed.

\section{Introduction}

\section{Contributors and deterrents of suicide}

Suicide is a major and potentially preventable health problem needing greater attention. It is the result of an interaction of multiple known and unknown contributors, deterrents, and acute triggers. Some of the well-recognized contributors to suicide include anhedonia, depression, psychosis, substance abuse, bipolar illness, panic attacks, posttraumatic stress disorder, obsessiveness, anxiety, agitation, impulsivity, aggressiveness, depersonalization, rigidity, narcissism, borderline personality, feelings of helplessness, hopelessness, repression, lack of outlets for frustration, sexual issues, boundary issues, other mental conditions, chronic pain, disability, neurological impairments, chronic medical problems, infections, immune reactions, genetic vulnerabilities, social isolation, adverse life events, abusive relationship(s), family dysfunction, family substance abuse, family mental illness, separation or divorce, exposure to trauma, abusive development (ie, child abuse or neglect), family history of mental illness or suicide, incarceration, legal problems, financial distress, prior suicide attempts, high crime rates and other broader community conditions, limited access to health and social services, and easy access by persons at risk to lethal means (ie, 90-day supplies of medication or unlocked firearm). ${ }^{1,2}$ Acute triggering events can include window of fear, exposure to the suicidal behavior of others, acute sleep deprivation, alcohol and/or drug intoxication or withdrawal, recent rejection, loss, embarrassment or failure, "intimate partner problems, physical health conditions, financial challenges, and legal problems". ${ }^{3}$ Deterrents to suicide include mental fitness, frustration tolerance, cognitive abilities, coping skills, parenthood, supportive relationships, community and other social connections, purpose, ethical and religious beliefs, good medical and neurological health, and access to social services and psychiatric and medical care. ${ }^{4}$

Understanding suicidality requires a very complex formula and is associated with many different sequential events, contributors, deterrents, and acute triggers which are both known and unknown. While acknowledging the significance of all of these other components to suicidality, the scope of this article shall specifically focus upon suicide and (LAD).

\section{Epidemiological statistics}

Suicide is a major public health concern; however, suicide statistics are significantly underreported. Suicidality statistics include those with suicidal thoughts, suicidal plans, suicidal attempts, self-harm injuries, and completed suicides. The 2014 US statistics show 9.3 million (3.9\%) have suicidal thoughts, 2.7 million (1.1\%) made a plan, 1.3 million $(0.6 \%)$ attempted suicide, 494,169 visited a hospital for self-harm injuries, and 42,773 completed suicide. ${ }^{5}$ A number of ratios are established which include 13/100,000 commit suicide per year, there are 25 attempts for every completed suicide, 12 people harm themselves for every completed suicide, and $0.3 \%$ of those with suicidal thoughts commit suicide per year. ${ }^{5}$

Based upon the CDC research, there are at least 329,000 cases of Lyme disease diagnosed per year, mostly in children and middle-age adults, but only $25,000-40,000$ per year meet their Surveillance Case Definition. ${ }^{6}$ According to the CDC, "Surveillance Case Definitions establish uniform criteria for disease reporting and should not be used as the sole criteria for establishing clinical diagnoses."

\section{Diagnosing LAD}

Any diagnosis is based upon a thorough clinical examination combined with physician judgment, and Lyme disease is no exception. Clinical practice guidelines may provide additional assistance. The US Agency for Healthcare Research and Quality maintains the National Guideline Clearinghouse and works closely with the Institute of Medicine to maintain standards for trustworthy evidencebased clinical practice guidelines which can assist with diagnosis. ${ }^{8}$ In the National Guideline Clearinghouse, the only guidelines specifically addressing Lyme disease are the ILADS Guidelines (2014), but the American Psychiatric Association Practice Guidelines for the Psychiatric Evaluation of Adults (2016) are also listed..$^{8-10}$ These guidelines recognize the value of a thorough clinical exam, mental status exam, pattern recognition, and clinical judgment, and the ILADS guidelines discuss laboratory assessment in determining the diagnosis. ${ }^{9,10}$

Although not currently recognized in the National Guideline Clearinghouse, many turn to the Infectious Diseases Society of America (IDSA) Lyme disease guidelines (2006) for guidance in diagnosing Lyme disease. ${ }^{11}$ The IDSA guidelines also recognize the value of a thorough clinical, laboratory assessment and physician judgment. They have a disclosure stating guidelines "are not intended to supplement physician judgment"; adherence to them are voluntary and their application is to be determined by the physician while recognizing "each patient's individual circumstances". ${ }^{11}$ 
For diagnosis, there are many similarities between the ILADS and IDSA guidelines, and a comprehensive clinical assessment is essential.

In addition to Borrelia burgdorferi, a number of other tick-borne coinfections, and secondary opportunistic infections, may also be diagnosed, which explains using the term "and associated diseases". ${ }^{9,11}$ B. burgdorferi may be diagnosed as a persistent infection with immune suppressant and evasive capabilities, ${ }^{12}$ or there may be a postinfectious process. In either case, the psychiatric symptoms are associated with an immune-mediated process. ${ }^{13-17}$

\section{Citations addressing suicide and LAD}

Currently, there are over 340 peer-reviewed international journal articles documenting psychiatric symptoms associated with LAD. ${ }^{18}$ Although some patients may have no, or minimal, symptoms following a tick bite, others develop significant symptoms over time, including a broad spectrum of psychiatric impairments, such as the development of suicidal risk. ${ }^{19}$ Combined homicide and suicide have also occurred. ${ }^{20}$ In a prior presentation, homicidal tendencies occurred in about $15 \%$ of late-stage Lyme/tick-borne disease patients, and most of these patients also had suicidal tendencies. ${ }^{21}$ No journal article has ever before performed a comprehensive assessment of the association between LAD and suicide.

Fourteen case reports in the international literature describe patients who became suicidal after acquiring LAD. ${ }^{22-35}$ Fourteen additional citations recognize the causal association between suicide and LAD..$^{15,16,36-47}$ One article reviewed the clinical course of 57 patients diagnosed with Lyme disease and documented four suicide attempts in the 57 patients. ${ }^{48}$ Five articles recognized that suicidality associated with LAD has an immune-mediated pathophysiology. $13,15,28,31,40$

Suicide as well as depression, anxiety, brain fog, paranoia, loss of mental capacities, and other mental symptoms were also reported to be associated with the Lyme vaccine clinical trial. The Adverse Event Reporting System described a 43-year-old man who committed suicide seven months after receiving the vaccine who described severe pain and an inability "to get relief from 14 different doctors he had seen". 29,49

Depression is a well-recognized contributor towards suicidal risk. In the general population, there is a $16.2 \%$ lifetime prevalence and a $6.6 \%$ prior 12 -month prevalence. ${ }^{50}$ Although depression is not prevalent in the early stages of LAD in patients who are diagnosed and treated early and effectively, ${ }^{51}$ in the later stages of LAD, the prevalence of depression is significantly higher with findings of $37 \%,{ }^{52}$ $37 \%,{ }^{53} 50 \%,{ }^{54} 51 \%,{ }^{55} 64 \%,{ }^{56} 47 \%$ (mood swings), ${ }^{57}$ and $80 \%$ (with intrusive symptoms). ${ }^{28}$ Intrusive symptoms can also contribute to causing suicide and violence, and $34 \%$ of patients with a history of LAD acquire intrusive symptoms. ${ }^{28}$ Among these patients, $69 \%$ become suicidal, while 31\% develop homicidal tendencies. ${ }^{28}$

A survey of a patient support group concluded hopelessness by lack of educated doctors, isolation, debilitating symptoms, depression caused by Lyme disease, feeling like a burden, and watching our friends die contributed to suicidal feeling in patients with LAD. ${ }^{58}$

\section{Environmental exposure and suicide}

Suicide risk is greater in outdoor workers, in particular forestry workers, and veterans. ${ }^{59-63}$ Recent studies demonstrated the rate of suicide was highest among persons working in the farming, fishing, and forestry group $(84.5 / 100,000)$, while the lowest rate was found in the education, training, and library occupational group $(7.5 / 100,000){ }^{64,65}$ While tick-borne disease exposure could be a contributor to those working in farming and forestry, it might not explain the high rate in fisherman ${ }^{66}$ Veterans can be at risk for tick-borne diseases from exposure during basic training and deployment; however, other causes of suicidality must also be considered, such as family disruption from deployment, being trained to kill, toxic exposure, and trauma. ${ }^{67}$

\section{Infections increasing suicidality}

Sickness syndrome is a well-recognized response to infection and is associated with anhedonia and depression, both of which are associated with suicidal risk. ${ }^{68}$ A number of infections have been associated with suicide including influenza, coronaviruses, cytomegalovirus, HIV/AIDS, Toxoplasma gondii, and hepatitis C. Latent infection with T. gondii is a prevalent condition that has been linked in humans to suicide and suicide attempts. T. gondii titers may quantify a proneness to suicidal behavior. In a sample of 20 European nations, the prevalence of $T$. gondii was positively associated with national suicide rates, and $T$. gondii seropositivity was associated with a sevenfold greater risk of self-directed violence. ${ }^{69-74}$

The Danish nationwide register studies demonstrate a strong correlation between infections requiring hospitalization and suicide. In one study, hospitalization for COPD was associated with a significantly increased risk for 
suicide. ${ }^{75}$ Another study looked at all infections requiring hospitalization and demonstrated an increased risk of dying by suicide was found among people with hospital contacts with infections. The relative risk of suicide was increased among individuals with any hospitalization with infections by $42 \%$ compared with individuals without prior infection; the greater the number of hospital contacts for infections and days spent in treatment, the greater the risk of death by suicide. The authors said "The highest risks of suicide were found among individuals with hepatitis infection and HIV/AIDS infection" and "It will be important to understand how milder and long-term infections contribute to depression and suicidality. Such infections often go untreated and remain latent in the body for years. ${ }^{976}$

\section{Psychoimmunology of suicide}

The infectious disease and suicide association is mediated by cytokine and other immune effects. Infections impact CNS functioning by provoking cytokines that "can modulate the concentration of monoaminergic neurotransmitters and their metabolites in various regions of the CNS". ${ }^{77}$ There is a significant body of research demonstrating a strong association between inflammation, brain inflammation, elevated cytokine levels, and suicide. ${ }^{78-80}$ "Most suicide attempters, or subjects with suicidal ideation, show an imbalance in the immune system." ${ }^{\text {"1 }}$ Interferon treatment for hepatitis $\mathrm{C}$ has been a clinical model demonstrating the significance of inflammation-mediated mental symptoms including suicide.$^{82}$ Cytokine activation has been associated with both suicide and self-harm behavior. " "IL-6 is elevated in the cerebrospinal fluid of suicide attempters and related to symptom severity." $\$ 4$ The brains of suicide victims had significantly increased microgliosis, which demonstrates the presence of brain inflammation, compared to subjects who died from other causes. ${ }^{85}$ "Increased levels of IL-1 $\beta$, IL-6 and TNF- $\alpha$ were shown in the anterior prefrontal cortex of teenage suicide victims." "Suicidal ideation was significantly associated with an elevated inflammatory index of C-reactive protein, IL-6, IL-10 and TNF- $\alpha$, in patients with depression. ${ }^{~} 87$ A meta-analysis on inflammation in suicidal patients demonstrated "there are aberrant cytokine levels in blood, cerebrospinal fluid (CSF) and postmortem brain samples from suicidal patients. The levels of IL- $1 \beta$ and IL-6 were most robustly associated with suicidality, and these cytokines may help distinguish suicidal from non-suicidal patients. ${ }^{\prime 88}$ In summary, conditions that cause brain inflammation can contribute significantly to suicidality. Lyme disease has been associated with the same proinflammatory cytokines TNF- $\alpha$, IL-1 $\beta$, and IL-6 that are associated with suicide $^{89}$

\section{LAD psychoimmunology and suicide}

There are multiple known and unknown mechanisms by which B. burgdorferi causes immune-mediated neuronal dysfunction resulting in clinical symptoms. Although some symptoms may be associated with infection within the brain or in the brain vasculature, infection in the periphery can also provoke significant immune activity that crosses the blood-brain barrier. ${ }^{13}$ These immune-mediated effects include activation of proinflammatory cytokines and increases in TNF- $\alpha$, IL-1 $\beta$, IL-6, IL-8, IL-12, IL-17, IL-18, interferon-gamma, neopterin, C-reactive protein, surface lipoprotein E, and the chemokines CXCL12 and CXCL13, release of proinflammatory lipoproteins from the outer coat of B. burgdorferi, immune effects from the flagella of B. burgdorferi, immune effects from outer surface protein A of B. burgdorferi inducing apoptosis and astrogliosis, autoimmune effects, direct cytotoxicity by proximity of B. burgdorferi to neurons and adherence to and invasion of neurons, interactions with Schwann and glial cells producing nitric oxide, the spirochetes locally inducing cytokines such as IL- 6 or TNF- $\alpha$ in glial cells, the secretion of cytotoxic substances by leucocytes and glial cells contributing to damage of oligodendrocytes that are vital for the functioning and survival of neurons, and other immune effects from the other known and unknown coinfections and opportunistic infections. ${ }^{13,17}$ In addition, metabolic pathophysiological changes are also associated with altered tryptophan metabolism, increases in quinolinic acid, oxidative stress, excitotoxicity, and changes in homocysteine metabolism. ${ }^{13,17,90}$

\section{Inflammatory-mediated changes in tryptophan metabolism, quinolinic acid, and glutamate}

The effects of inflammation on mood and behavior could partially be mediated by the effects upon tryptophan metabolism, kynurenine pathway metabolites, and glutamate neurotransmission. Inflammation increases indoleamine 2,3dioxygenase which shifts tryptophan metabolism away from serotonin and melatonin towards an increase of quinolinic acid. Quinolinic acid correlates significantly with guilt, and the ratio of quinolinic acid/3-hydroxykynurenine correlates significantly with guilt and psychomotor agitation. ${ }^{91}$ Quinolinic acid levels also correlate with increased suicidal risk. ${ }^{92}$ High cerebrospinal fluid quinolinic acid levels correlate with high suicidal intent. ${ }^{93}$ Quinolinic acid levels have 
been demonstrated to be continuously elevated in the patients who had suicide attempts, and the levels were highest in close proximity to the attempt. ${ }^{94}$ Quinolinic acid is an NMDA receptor agonist which leads to an excess of calcium influx into neurons. Quinolinic acid levels are increased, while kynurenic acid, an NMDA receptor antagonist, is decreased in suicidal patients which supports a role for a glutamatergic mechanism in suicidality. Severe depression is associated with increased microglial quinolinic acid in subregions of the anterior cingulate gyrus and the anterior midcingulate cortex compared to controls. ${ }^{95}$ Quinolinic acid in cerebrospinal fluid is increased in a number of chronic infections including B. burgdorferi infections and correlates with "symptom severity" and "pathological potential".96,97

\section{Altered neural circuits increasing suicidality}

Decreased structural and functional connectivity in the amygdala-prefrontal neural system impairs emotional regulation and is associated with increased suicide risk. ${ }^{98}$ The cingulate cortex is known to recruit other brain regions in response to conflict. ${ }^{99}$ Brain regions and circuits associated with impulsive aggressiveness and self-directed aggressiveness involve an interaction between the orbital frontal cortex, the anterior cingulate cortex, and the amygdala. The orbital frontal cortex is significant in restraining impulsive outbursts, while the anterior cingulate cortex coordinates other brain regions in response to conflict. The amygdala is involved in fear response and other aversive emotions. In impulse-prone individuals, there is decreased activity in the orbital frontal cortex and/or anterior cingulate combined with normal or increased activity of the amygdala which demonstrates how these two restraining brain regions are not adequately counteracting the fear response when something is perceived and threatening and this can result in explosive and impulsive behavior. ${ }^{100}$ It has been found that decreased white matter integrity and density in the superior longitudinal fasciculus is associated with intermittent explosive disorder. ${ }^{101}$ LAD has been associated with a predominately white matter encephalopathy with white matter-processing impairments. ${ }^{102}$

\section{Methods}

A pilot study was performed to review clinical data. This consisted of a retrospective review of randomly selected inactive charts of patients with LAD from the author's practice with their identity protected. These patients were evaluated with a comprehensive assessment including premorbid assessment, history of tick exposure, history of the presence of erythema migrans rash, early tick-borne disease symptoms, symptoms in the course of illness, and current status with a comprehensive neuropsychiatric and general medical assessment and review of systems using the 280-item Neuropsychiatric Lyme Assessment with pattern recognition and a review of laboratory assessment, which may include enzyme-linked immune assay, immunofluorescent assay, Western blot, DNA-based testing, coinfection testing, single-photon emission tomography, magnetic resonance imaging, or other diagnostic testing to determine the diagnosis..$^{8-11,103,104}$ Only testing from laboratories validated by the Clinical Laboratory Improvement Amendments of the US Department of Health and Human Services Centers for Medicare and Medicaid Services was considered valid. Charts in which the diagnosis of Lyme disease was unclear were excluded from the study. The 253 charts that met the criteria were divided into four groups based upon symptoms suicidal and homicidal, suicidal not homicidal, experiencing explosive anger not suicidal or homicidal, and not suicidal, homicidal, or experiencing explosive anger. The patients who were both suicidal and homicidal were considered to be the most severe cases, while the patients who were least severe were the patients who were not homicidal, suicidal, or experiencing explosive anger. Names were converted to an identifier before entering findings into a database of individual participant data. Clinical findings most relevant to the diagnosis and suicidal risk were analyzed. All 29 of the suicidal and homicidal charts were reviewed, and a representative sample of 20 charts from the suicidal group was pulled at random from the suicidal but not homicidal group and 20 charts were pulled at random from the not suicidal, homicidal, or experiencing explosive anger group. A comparison of individual participant data is made by comparing the findings for all patients suicidal and homicidal $(\mathrm{N}=29)$ to the findings for those suicidal and not homicidal $(\mathrm{N}=20)$ and not homicidal or suicidal or experiencing explosive anger $(\mathrm{N}=20)$. The premorbid health status is the control for each group and is shown in parentheses in Figure 1. Symptoms associated with risk were ranked by comparing the prevalence of different findings among the three different groups. Two representative cases of suicidal LAD patients are described. In the case reviews, identifying information was removed to conceal identities. In the nonfatal case, written consent was obtained for publication. In the fatal case, written consent from the next of kin was obtained for publication.

Since there are no databases of LAD suicides, the prevalence can only be estimated indirectly by using CDC statistics of Lyme disease, calculating the percent with 


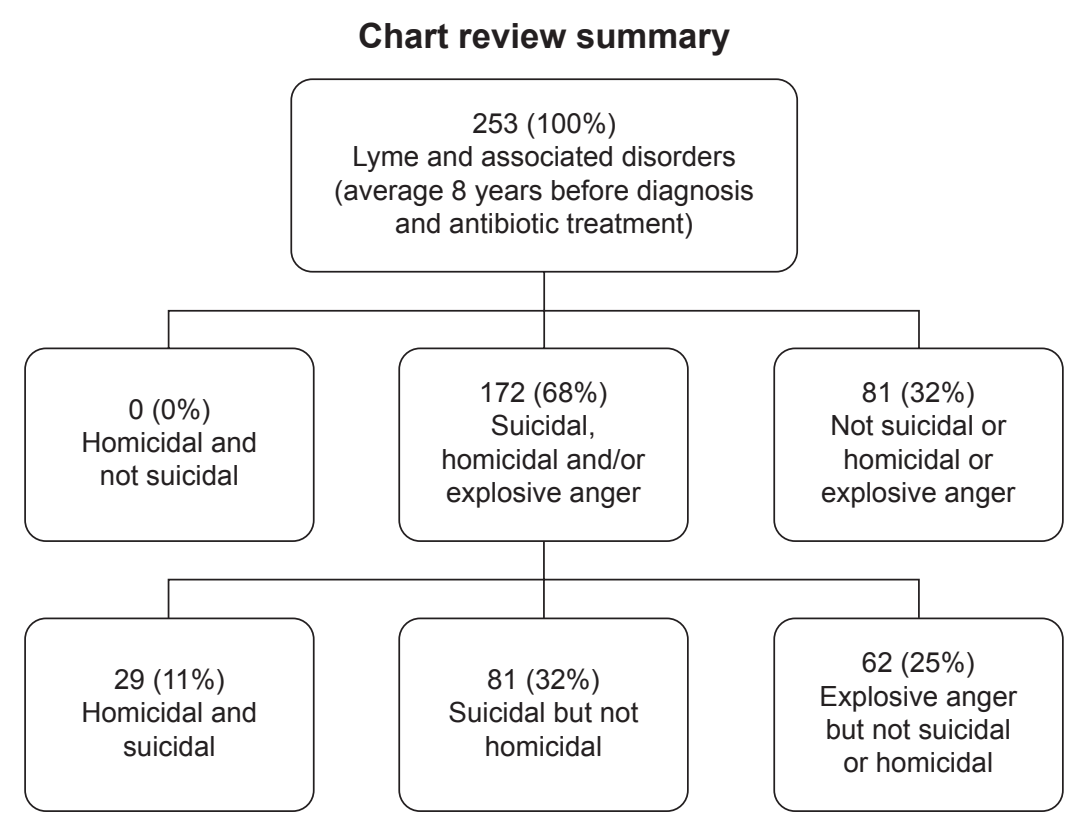

Figure I Chart review flowsheet.

persistent symptoms that occur each year, multiplying this number by the duration based on the medical literature, and multiplying this by the percent of patients with suicidal thoughts to determine the number of patients with Lyme disease and suicidal thoughts. The CDC statistics of the ratios of patients with suicidal thoughts to those who completed suicides were used to calculate the estimated number of patients with LAD and suicidal thoughts who completed suicide per year in the US.

The Meridian Health Institutional Review Board, Neptune, NJ, USA, approved this study (IRB \# 201704192J), as exempted. Patient consent to review their medical records was not required as there was minimal risk to subjects, no subject identifiers or links to identifiers were used or collected, and it was a retrospective chart review of already existing data. In the case reports, the next of kin of the deceased patient signed a consent to publish the case, and the patient who survived signed a consent to publish the case.

\section{Results}

\section{Chart review}

A review of 253 inactive charts of patients with LAD (58\% female, $42 \%$ male, age 8-64 years, average age 39 years) from the investigator's practice demonstrated an average of 8 years before diagnosis and initiating treatment for LAD. All of these patients met the clinical criteria for the diagnosis of LAD. Many had a history of erythema migrans rashes; all had objective clinical findings; most had laboratory confirmation and were tested positive for B. burgdorferi; some had findings demonstrated by single photon emission tomography, magnetic resonance imaging, and/or spinal taps, and most tested positive for a number of coinfections which included Babesia, Bartonella, Anaplasma, Ehrlichia chaffeensis, Rickettsia rickettsii, Epstein-Barr virus, cytomegalovirus, human herpesvirus-2, Mycoplasma pneumonia, Chlamydophila pneumoniae, and hepatitis $\mathrm{C}$ virus. The laboratory assessment of these patients was often performed before referral to the investigator.

Many patients fulfilled CDC Surveillance Case Definition, while in other patients, Surveillance Case Definition was not used as the sole criteria for establishing the clinical diagnosis. ${ }^{7}$ It is recognized Lyme disease Surveillance Case Definition based upon immune-based two-tier testing has a very low sensitivity $(46 \%)^{105}$ and "generated over 500 times false-negative results than two stage HIV testing". ${ }^{106}$ The limitations of this testing are understandable since two-tier Lyme testing is an immune-based test for a highly adaptive spirochete that is well known to suppress and evade the immune system. ${ }^{12,107,108}$ This also explains the disparity between the number of CDC Surveillance Case Definition cases and the actual cases of Lyme disease each year. ${ }^{6,7}$ Comparing these two groups was not the purpose of this study; however, the only distinction that could be seen between these two groups in the clinical presentation was a higher prevalence of periostitis in the patients fulfilling CDC Surveillance Case Definition. 
Of the 253 patients, $68 \%(\mathrm{~N}=172)$ were suicidal, homicidal, and/or had explosive anger, while $32 \%(\mathrm{~N}=81)$ were nether suicidal and homicidal nor had explosive anger. On looking at the 172 patients in greater detail, $43 \%$ of the $253(\mathrm{~N}=110)$ were suicidal, 32\% $(\mathrm{N}=81)$ were suicidal but not homicidal, and $11 \%(\mathrm{~N}=29)$ were both suicidal and homicidal. Moreover, none of the 253 patients were homicidal without also being suicidal, and $25 \%$ of the $253(\mathrm{~N}=62)$ had explosive anger but were neither suicidal nor homicidal (Figure 1).

Among the 109 patients who were suicidal, 26\% (N=29) were also homicidal. A review of patients who were both suicidal and homicidal demonstrated an average of 8.4 years before diagnosis and initiating LAD treatment. Of all the patients, $10 \%$ had preexisting depression. After infection, $97 \%$ of this group had depression. One patient (4\%) had preexisting suicidal and homicidal tendencies, but the date of onset of the infection was unclear in this patient and may have preceded the onset of these symptoms.

In the chart review of LAD patients, a higher level of risk to self and others in the order of significance was associated with the presence of explosive anger, intrusive images, sudden mood swings, paranoia, dissociative episodes, hallucinations, disinhibition, panic disorder, rapid cycling bipolar, depersonalization, social anxiety disorder, substance abuse, hypervigilance, generalized anxiety disorder, genital-urinary symptoms, chronic pain, anhedonia, depression, low frustration tolerance, posttraumatic stress disorder, obsessive compulsive disorder, cardiac symptoms, cognitive symptoms, musculoskeletal symptoms, and fatigue, but not gastrointestinal symptoms, vegetative symptoms, pulmonary/upper respiratory symptoms, or neurological symptoms (Table 1). Very few of these conditions were present in these patients before they were infected with LAD (Table 2).

\section{Case reviews}

\section{A patient who committed suicide}

The patient was infected 10 years before being diagnosed with Lyme disease with coinfections with clinical symptoms and laboratory confirmation. Before diagnosis, there was a progressively increasing onset of multiple symptoms that included attention span impairments, executive dysfunction, sensory hyperacusis, memory impairments, slow processing, depersonalization, derealization, aggressive intrusive thoughts and images, dissociative episodes, illusions, hallucinations, decreased frustration tolerance, feeling overwhelmed, sudden
Table I Higher-risk vs lower-risk groups

\begin{tabular}{|c|c|c|c|}
\hline Clinical finding & $\begin{array}{l}\text { Suicidal and } \\
\text { homicidal }\end{array}$ & Suicidal & $\begin{array}{l}\text { Not suicidal, } \\
\text { homicidal, } \\
\text { or aggressive }\end{array}$ \\
\hline Hallucinations & $45 \%(0 \%)$ & $25 \%(0 \%)$ & $0 \%(0 \%)$ \\
\hline Explosive anger & $83 \%(4 \%)$ & $60 \%(0 \%)$ & $0 \%(0 \%)$ \\
\hline Dissociative episodes & $18 \%(4 \%)$ & $5 \%(0 \%)$ & $0 \%(0 \%)$ \\
\hline Paranoia & $76 \%(0 \%)$ & $25 \%(0 \%)$ & $10 \%(0 \%)$ \\
\hline Disinhibition & $80 \%(0 \%)$ & $35 \%(0 \%)$ & $20 \%(0 \%)$ \\
\hline Intrusive images & $48 \%(0 \%)$ & $0 \%(0 \%)$ & $5 \%(0 \%)$ \\
\hline Rapid cycling bipolar & $21 \%(0 \%)$ & $20 \%(0 \%)$ & $5 \%(0 \%)$ \\
\hline Sudden mood swings & $93 \%(0 \%)$ & $85 \%(0 \%)$ & $15 \%(0 \%)$ \\
\hline Panic disorder & $80 \%(4 \%)$ & $50 \%(0 \%)$ & $35 \%(5 \%)$ \\
\hline Depersonalization & $76 \%(4 \%)$ & $55 \%(0 \%)$ & $40 \%(0 \%)$ \\
\hline Substance abuse & $28 \%(8 \%)$ & $5 \%(0 \%)$ & $10 \%(5 \%)$ \\
\hline Social anxiety & $55 \%(0 \%)$ & $65 \%(10 \%)$ & $20 \%(0 \%)$ \\
\hline Hypervigilance & $72 \%(0 \%)$ & $55 \%(5 \%)$ & $35 \%(0 \%)$ \\
\hline Generalized anxiety & $90 \%(4 \%)$ & $65 \%(0 \%)$ & $50 \%(5 \%)$ \\
\hline Anhedonia & $72 \%(4 \%)$ & $85 \%(0 \%)$ & $59 \%(5 \%)$ \\
\hline $\begin{array}{l}\text { Genital-urinary } \\
\text { symptoms }\end{array}$ & $59 \%(5 \%)$ & $80 \%(5 \%)$ & $45 \%(0 \%)$ \\
\hline Chronic pain & $57 \%(0 \%)$ & $65 \%(0 \%)$ & $35 \%(0 \%)$ \\
\hline Depression & $97 \%(10 \%)$ & $100 \%(15 \%)$ & $80 \%(5 \%)$ \\
\hline $\begin{array}{l}\text { Low frustration } \\
\text { tolerance }\end{array}$ & $100 \%(0 \%)$ & $90 \%(0 \%)$ & $80 \%(0 \%)$ \\
\hline $\begin{array}{l}\text { Posttraumatic stress } \\
\text { disorder }\end{array}$ & $24 \%(17 \%)$ & $15 \%(0 \%)$ & $15 \%(15 \%)$ \\
\hline $\begin{array}{l}\text { Obsessive } \\
\text { compulsive disorder }\end{array}$ & $48 \%(0 \%)$ & $30 \%(10 \%)$ & $35 \%(0 \%)$ \\
\hline Cardiac symptoms & $63 \%(8 \%)$ & $50 \%(0 \%)$ & $50 \%(0 \%)$ \\
\hline Cognitive symptoms & $100 \%(4 \%)$ & $100 \%(0 \%)$ & $85 \%(0 \%)$ \\
\hline $\begin{array}{l}\text { Gastrointestinal } \\
\text { symptoms }\end{array}$ & $71 \%(4 \%)$ & $85 \%(0 \%)$ & $75 \%(5 \%)$ \\
\hline $\begin{array}{l}\text { Musculoskeletal } \\
\text { symptoms }\end{array}$ & $100 \%(0 \%)$ & $90 \%(0 \%)$ & $90 \%(0 \%)$ \\
\hline Fatigue & $97 \%(0 \%)$ & $85 \%(0 \%)$ & $85 \%(0 \%)$ \\
\hline Vegetative symptoms & $100 \%(0 \%)$ & $95 \%(0 \%)$ & $100 \%(0 \%)$ \\
\hline $\begin{array}{l}\text { Pulmonary/upper } \\
\text { respiratory }\end{array}$ & $66 \%(8 \%)$ & $70 \%(0 \%)$ & $70 \%(5 \%)$ \\
\hline $\begin{array}{l}\text { Neurological } \\
\text { symptoms }\end{array}$ & $86 \%(0 \%)$ & $95 \%(0 \%)$ & $90 \%(0 \%)$ \\
\hline
\end{tabular}

Note: Data in parentheses report the findings before infection.

abrupt mood swings, agitation, hypervigilance, paranoia, disinhibition, explosive anger, suicidal thoughts, guilt, substance abuse, crying spells, depression, anhedonia, apathy, panic attacks, agoraphobia, social anxiety, generalized anxiety, posttraumatic stress disorder, non-restorative sleep, anorexia, decreased libido, night sweats, headaches, cranial nerve symptoms, neuropathy, burning hands and feet, fatigue, weakness, tremors, twitching, myoclonic jerks, musculoskeletal symptoms, racing pulse, irritable gut, and spastic bladder. The patient had limited response to psychiatric treatments, and antibiotics resulted in extreme JarischHerxheimer reactions with increased severity of symptoms. 
Table 2 Findings in the groups before infection

\begin{tabular}{|c|c|c|c|}
\hline Clinical finding & $\begin{array}{l}\text { Suicidal and } \\
\text { homicidal }\end{array}$ & Suicidal & $\begin{array}{l}\text { Not suicidal, } \\
\text { homicidal, } \\
\text { or aggressive }\end{array}$ \\
\hline Hallucinations & $0 \%$ & $0 \%$ & $0 \%$ \\
\hline Explosive anger & $4 \%$ & $0 \%$ & $0 \%$ \\
\hline Dissociative episodes & $4 \%$ & $0 \%$ & $0 \%$ \\
\hline Paranoia & $0 \%$ & $0 \%$ & $0 \%$ \\
\hline Disinhibition & $0 \%$ & $0 \%$ & $0 \%$ \\
\hline Intrusive images & $0 \%$ & $0 \%$ & $0 \%$ \\
\hline Rapid cycling bipolar & $0 \%$ & $0 \%$ & $0 \%$ \\
\hline Sudden mood swings & $0 \%$ & $0 \%$ & $0 \%$ \\
\hline Panic disorder & $4 \%$ & $0 \%$ & $5 \%$ \\
\hline Depersonalization & $4 \%$ & $0 \%$ & $0 \%$ \\
\hline Substance abuse & $8 \%$ & $0 \%$ & $5 \%$ \\
\hline Social anxiety & $0 \%$ & $10 \%$ & $0 \%$ \\
\hline Hypervigilance & $0 \%$ & $5 \%$ & $0 \%$ \\
\hline Generalized anxiety & $4 \%$ & $0 \%$ & $5 \%$ \\
\hline Anhedonia & $4 \%$ & $0 \%$ & $5 \%$ \\
\hline $\begin{array}{l}\text { Genital-urinary } \\
\text { symptoms }\end{array}$ & $5 \%$ & $5 \%$ & $0 \%$ \\
\hline Chronic pain & $0 \%$ & $0 \%$ & $0 \%$ \\
\hline Depression & $10 \%$ & $15 \%$ & $5 \%$ \\
\hline $\begin{array}{l}\text { Low frustration } \\
\text { tolerance }\end{array}$ & $0 \%$ & $0 \%$ & $0 \%$ \\
\hline $\begin{array}{l}\text { Posttraumatic stress } \\
\text { disorder }\end{array}$ & $17 \%$ & $0 \%$ & $15 \%$ \\
\hline $\begin{array}{l}\text { Obsessive compulsive } \\
\text { disorder }\end{array}$ & $0 \%$ & $10 \%$ & $0 \%$ \\
\hline Cardiac symptoms & $8 \%$ & $0 \%$ & $0 \%$ \\
\hline Cognitive symptoms & $4 \%$ & $0 \%$ & $0 \%$ \\
\hline $\begin{array}{l}\text { Gastrointestinal } \\
\text { symptoms }\end{array}$ & $4 \%$ & $0 \%$ & $5 \%$ \\
\hline $\begin{array}{l}\text { Musculoskeletal } \\
\text { symptoms }\end{array}$ & $0 \%$ & $0 \%$ & $0 \%$ \\
\hline Fatigue & $0 \%$ & $0 \%$ & $0 \%$ \\
\hline Vegetative symptoms & $0 \%$ & $0 \%$ & $0 \%$ \\
\hline $\begin{array}{l}\text { Pulmonary/upper } \\
\text { respiratory }\end{array}$ & $8 \%$ & $0 \%$ & $5 \%$ \\
\hline Neurological symptoms & $0 \%$ & $0 \%$ & $0 \%$ \\
\hline
\end{tabular}

Some treatments were denied by the insurance company, and disability coverage was denied. The patient became increasingly disabled and demoralized. After three failed attempts, a suicide plan that had been in place for an extended period of time was implemented.

\section{A veteran who almost committed suicide}

In the words of the patient,

I woke up on a beach out of the country with a bottle of scotch in one hand and my handgun in the other. I did not remember driving there. My doctor said I was in a psychogenic fugue state. My life was being destroyed by Lyme disease and no one had a clue. At work, I had been highly awarded throughout my career but it became a real struggle and I did not understand why. When I went to work that morning, I was tired, frustrated and in a state of dread and fear and I drove 100 miles past the base. I only drank a small amount of the scotch; the bottle was still nearly full. I have never been a big drinker and as a result I fell asleep on the beach. I woke up the next day wondering how I got there and why and drove back to the base and turned myself in for Away Without Leave (AWOL). After being diagnosed, treated and having recovered, I can relate to other veterans living with undiagnosed and untreated Lyme disease.

\section{Summarizing case review results}

There are many patterns of suicide seen in LAD patients, and the cases described represent the two most common patterns of suicide that have been observed. These cases demonstrate not all patients follow the same pattern in the development of suicidal risk. In the first case, the suicide risk evolved and increased over an extended period of time and was well planned with an overwhelming severity of multiple symptoms including all of the symptoms associated with suicidality that were demonstrated in the chart review. This case had similarities to the suicide case described in the Lyme vaccine trials. The second case was unpredictable with no advanced planning, and these cases are often bizarre and senseless. In this case, there appeared to be an acute trigger, possibly sleep deprivation, which is a recognized trigger for suicidal behavior in the presence of other psychiatric risks for suicide. ${ }^{109}$

\section{Lyme disease statistics relevant to suicide} It has been calculated that $28 \%$ of Lyme patients progress to develop chronic symptoms, ${ }^{110,111}$ nearly half of the patients had Lyme disease for more than 10 years before their initial diagnosis, ${ }^{112}$ once depression occurs it tends to persist,,${ }^{113}$ and psychiatric symptoms associated with LAD often persist in spite of antibiotic treatment. ${ }^{114,115}$ A prior study demonstrated $41 \%$ of children who had been diagnosed with Lyme disease had suicidal thoughts and $11 \%$ had made suicidal gestures, ${ }^{116}$ another study demonstrated $33 \%$ of late-stage Lyme disease patients were suicidal, ${ }^{21}$ and another study demonstrated $18 \%$ of posttreatment Lyme disease patients hade suicidal ideations, ${ }^{117}$ while another study demonstrated $69 \%$ of Lyme/tick-borne disease patients with intrusive symptoms had suicidal thoughts. ${ }^{28}$

\section{Possible prevalence of suicidality associated with LAD}

There are no direct records of the number of LAD patients who commit suicide. Therefore, an indirect method is implemented to estimate the possible prevalence of suicidality 
associated with LAD. Using the statistics previously stated in this article and the CDC statistic of at least 329,000 cases per year of Lyme disease and recognizing that initial infections occur mostly in children and middle-age adults, it has previously been calculated that $28 \%$ of Lyme patients progress to develop chronic symptoms which would mean at least 92,120 per year go on to develop chronic symptoms. ${ }^{6,108}$ Of the total number of patients, $48 \%$ go 10 or more years before their initial diagnosis, and symptoms (including psychiatric symptoms) often persist when there has been a significant delay in initiating antibiotic treatment. ${ }^{12}$ Since many are relatively young with significant longevity, it is estimated the average duration of illness is at least 25 years which calculates to 2,303,000 having chronic symptoms. Studies previously discussed demonstrated persistent suicidal ideations were present in 33\%, 69\% (with intrusive symptoms), $18 \%$ and $43 \%$ in the chart review in this article..$^{21,28,117}$ I shall use the most restrictive number of $18 \%$ of posttreatment Lyme disease patients having suicidal ideations which calculates to 414,540 LAD patients with suicidal ideations. ${ }^{117}$ When using this number with the suicidality ratio of $0.3 \%$ with suicidal ideations of committing suicide per year and other ratios, it calculates to 1,244 suicides, 14,928 self-harm events, 31,100 suicide attempts, and 414,540 patients with suicidal ideations in the US per year from LAD, based on indirect calculations. ${ }^{5}$ This number would be higher when adding undiagnosed and untreated cases with persistent symptoms and when adding those attributed to the coinfections and other associated diseases that may be seen in patients with Lyme disease.

\section{Conclusion}

LAD contributes to causing suicidal tendencies, suicide, and combined suicidal and homicidal tendencies in individuals who did not show these tendencies before being infected. Suicide risk is greater in veterans and outdoor workers, both of whom have greater exposure to LAD. Multiple case reports and other journal articles recognize a causal association between suicidal risk and LAD. LAD has been associated with an increased risk of depression in a number of different studies and has also been associated with intrusive symptoms, both of which are associated with an increased risk of suicide. A suicide was reported in the Lyme vaccine clinical trial.

Multiple studies link infections, in particular chronic infections, and the associated proinflammatory cytokines, and metabolic changes and neural circuit dysfunction with increased risk of suicidal behavior. It appears that suicide with infectious diseases and LAD share common immune, quinolinic acid, glutamate, and neural dysfunction-mediated

Lyme and associated diseases infection $\rightarrow$
Persistent proinflammatory cytokines $\rightarrow$
Dysregulation of tryptophan metabolism $\rightarrow$
Quinolinic acid $\rightarrow$ NMDA receptor agonism $\rightarrow$
Glutamate dysregulation $\rightarrow$
Neural circuit dysfunction $\rightarrow$
Psychiatric dysfunction $\rightarrow$
Suicidal, sometimes also homicidal

Figure 2 The death formula.

Abbreviation: NMDA, N-methyl-D-aspartate.

pathophysiology resulting in a broad spectrum of psychiatric and other symptoms that can be associated with increased suicidal risk. Tick-borne and other coinfections may further contribute to increasing symptoms (Figure 2).

The chart review of 253 patients generally reflects the findings in the medical literature. In the chart review, the patients were infected an average of 8 years before diagnosis and antibiotic treatment, and $43 \%$ had suicidal tendencies. In addition, $26 \%$ of these suicidal patients were also homicidal, but there were no patients who were homicidal without also being suicidal.

A higher level of risk of harm is associated with the presence of a number of conditions acquired as part of LAD and include explosive anger, intrusive images, sudden mood swings, paranoia, dissociative episodes, hallucinations, disinhibition, panic disorder, rapid cycling bipolar, depersonalization, social anxiety disorder, substance abuse, hypervigilance, generalized anxiety disorder, genital-urinary symptoms, chronic pain, anhedonia, depression, low frustration tolerance, posttraumatic stress disorder, obsessive compulsive disorder, cardiac symptoms, cognitive symptoms, musculoskeletal symptoms, and fatigue, but not gastrointestinal symptoms, vegetative symptoms, pulmonary/upper respiratory symptoms, or neurological symptoms.

Some LAD suicides are associated with being overwhelmed by severe, multiple neuropsychiatric, and general medical symptoms.

Other LAD suicides are impulsive, bizarre, senseless, and difficult to predict. It is possible that disabling symptoms, feeling like a burden, and negative attitudes about Lyme disease from family, friends, doctors, and/or the health care system may also contribute to suicidal risk.

The prevalence of LAD suicides calculated by an indirect method is estimated to be possibly 1,244 suicides and 414,540 patients with suicidal ideations in the US per year from LAD.

A means of acquiring accurate direct statistics of suicide and LAD is needed. It is suggested medical examiners, the 
$\mathrm{CDC}$, and other epidemiological organizations proactively evaluate the association between LAD and suicide. Better recognition of the significance of $\mathrm{LAD}$, earlier diagnosis and treatment, better understanding of the pathophysiology of suicide, and screening for suicide risk in LAD patients are also needed.

\section{Abbreviations}

CDC, Centers for Disease Control and Prevention; IDSA, Infectious Diseases Society of America; IL, interleukin; ILADS, International Lyme and Associated Diseases Society; LAD, Lyme and associated diseases; NMDA, N-methyl-Daspartate; TNF- $\alpha$, tumor necrosis factor-alpha.

\section{Acknowledgments}

The author expresses his appreciation to Lorraine Johnson, JD, MBA, Andy Kogelnik, MD, PhD, Douglas Bransfield, MBA, JD, and Barbara Rosenthal for their assistance. He would like to acknowledge the memory of many fine individuals whose lives were lost by suicide and the challenge of those currently affected by suicidal thoughts.

\section{Disclosure}

The author has been an expert witness in cases involving suicide and in cases involving Lyme disease. He reports no other conflicts of interest in this work.

\section{References}

1. Caine ED. Forging an agenda for suicide prevention in the United States. Am J Public Health. 2013;103(5):822-829.

2. Hom MA, Stanley IH, Gutierrez PM, Joiner TE Jr. Exploring the association between exposure to suicide and suicide risk among military service members and veterans. J Affect Disord. 2017;207:327-335.

3. Lyons BH, Fowler KA, Jack SP, Betz CJ, Blair JM. Surveillance for violent deaths - national violent death reporting system, 17 states, 2013. MMWR Surveill Summ. 2016;65(10):1-42.

4. Conway PM, Erlangsen A, Teasdale TW, Jakobsen IS, Larsen KJ. Predictive validity of the Columbia-Suicide Severity Rating Scale for short-term suicidal behavior: a Danish study of adolescents at a high risk of suicide. Arch Suicide Res. 2016:1-15.

5. CDC. National suicide statistics. 2016. Available from: http://www.cdc. gov/violenceprevention/suicide/statistics. Accessed March 3, 2017.

6. Nelson CA, Saha S, Kugeler KJ, et al. Incidence of clinician-diagnosed Lyme disease, United States, 2005-2010. Emerg Infect Dis. 2015;21(9): $1625-1631$.

7. CDC. Lyme disease: case definition and report forms. Available from: https://www.cdc.gov/lyme/stats/forms.html. Accessed May 5, 2017.

8. AHRQ. National Guideline Clearinghouse. 2016. Available from: https://www.guideline.gov. Accessed April 30, 2017.

9. Cameron DJ, Johnson LB, Maloney EL. Evidence assessments and guideline recommendations in Lyme disease: the clinical management of known tick bites, erythema migrans rashes and persistent disease. Expert Rev Anti Infect Ther. 2014;12(9):1103-1135.

10. The American Psychiatric Association practice guidelines for the psychiatric evaluation of adults. Third edition. 2016. Available from: http:// psychiatryonline.org/doi/pdf/10.1176/appi.books. 9780890426760. Accessed March 3, 2017.
11. Wormser GP, Dattwyler RJ, Shapiro ED, et al. The clinical assessment, treatment, and prevention of Lyme disease, human granulocytic anaplasmosis, and babesiosis: clinical practice guidelines by the Infectious Diseases Society of America. Clin Infect Dis. 2006;43(9): 1089-1134.

12. Berndtson K. Review of the evidence for immune evasion and persistent infection in Lyme disease. Int J Gen Med. 2013;6:291-306.

13. Bransfield RC. The psychoimmunology of Lyme/tick-borne diseases and its association with neuropsychiatric symptoms. Open Neurol J. 2012; 6:88-93.

14. Fallon BA, Levin ES, Schweitzer PJ, Hardesty D. Inflammation and central nervous system Lyme disease. Neurobiol Dis. 2010;37(3): 534-541.

15. Bransfield RC. Relationship of inflammation and autoimmunity to psychiatric sequelae in Lyme disease. Psychiatr Ann. 2012;42(9): 337-341.

16. Bransfield RC. The psychoimmunology of Lyme and associated diseases. Neurol Psychiatry Brain Res. 2014;20(1):8.

17. Ramesh G, Didier PJ, England JD, et al. Inflammation in the pathogenesis of Lyme neuroborreliosis. Am J Pathol. 2015;185(5): $1344-1360$.

18. Bransfield RC. List of 700 articles citing chronic infection associated with tick-borne diseases compiled by Dr. Robert Bransfield. ILADS; 2015. Available from: http://www.ilads.org/ilads_news/wp-content/ uploads/2017/02/CLDList-ILADS.pdf. Accessed March 3, 2017.

19. Fallon BA, Nields JA. Lyme disease: a neuropsychiatric illness. Am J Psychiatry. 1994;151(11):1571-1583.

20. Bransfield R. Can infections and immune reactions to them cause violent behavior? Paper presented at: Lyme Disease Conference; October 29, 2011; Toronto, ON.

21. Bransfield RC. A structured clinical interview when neuropsychiatric Lyme disease is a diagnostic possibility. Paper presented at: LDF's 10th Annual International Scientific Conference on Lyme Borreliosis and Other Tick-borne Disorders; April 28, 1997; Bethesda, MD.

22. Banerjee R, Liu JJ, Minhas HM. Lyme neuroborreliosis presenting with alexithymia and suicide attempts. J Clin Psychiatry. 2013; 74(10):981.

23. Stein SL, Solvason HB, Biggart E, Spiegel D. A 25-year-old woman with hallucinations, hypersexuality, nightmares, and a rash. Am J Psychiatry. 1996;153(4):545-551.

24. Fallon BA, Schwartzberg M, Bransfield R, et al. Late-stage neuropsychiatric Lyme borreliosis. Differential diagnosis and treatment. Psychosomatics. 1995;36(3):295-300.

25. Grzywa A, Karakuła H, Górecka J, Chuchra M. [Delusional disorders in the course of tick-born encephalitis and borreliosis in patients with hemophilia A and posttraumatic epilepsy - diagnostic and therapeutic difficulties]. Pol Merkur Lekarski. 2004;16(91):60-63. Polish [with English abstract].

26. Garakani A, Mitton AG. New-onset panic, depression with suicidal thoughts, and somatic symptoms in a patient with a history of Lyme disease. Case Rep Psychiatry. 2015;2015:457947.

27. Sattar $S$, Shah I. Bitten and forgotten: a case of early Lyme encephalitis. J Invest Med. 2016;55(1):S110.

28. Bransfield RC. Intrusive symptoms and infectious encephalopathies. Neurol Psychiatry Brain Res. 2016;22:3-4.

29. Lathrop SL, Ball R, Haber P, et al. Adverse event reports following vaccination for Lyme disease: December 1998-July 2000. Vaccine. 2002;20(11-12):1603-1608.

30. Coyle PK, Schutzer SE, Deng Z, et al. Detection of Borrelia burgdorferispecific antigen in antibody-negative cerebrospinal fluid in neurologic Lyme disease. Neurology. 1995;45(11):2010-2015.

31. Mattingley DW, Koola MM. Association of Lyme disease and schizoaffective disorder, bipolar type: is it inflammation mediated? Indian $J$ Psychol Med. 2015;37(2):243-246.

32. Radzišauskienė D, Ambrozaitis A, Marciuškienė E. Delayed diagnosis of Lyme neuroborreliosis presenting with abducens neuropathy without intrathecal synthesis of Borrelia antibodies. Medicina (Kaunas). 2013; 49(2):89-94. 
33. Leedy MJ, Jackson M, Callahan JL. Treating depression and compensatory narcissistic personality style in a man with chronic Lyme disease. Clin Case Stud. 2007;6(5):430-442.

34. Bär KJ, Jochum T, Häger F, Meissner W, Sauer H. Painful hallucinations and somatic delusions in a patient with the possible diagnosis of neuroborreliosis. Clin J Pain. 2005;21(4):362-363.

35. Gamstorp I. Lyme borreliosis from a patient's view-point. Scand J Infect Dis Suppl. 1991;77:15-16.

36. Bransfield RC. Diagnosis, treatment, and prevention of Lyme disease. JAMA. 1998;280(12):1049; author reply 1051.

37. Gerstenblith TA, Stern TA. Lyme disease: a review of its epidemiology, evaluation, and treatment. Psychosomatics. 2014;55(5): 421-429.

38. Cameron DJ. Proof that chronic Lyme disease exists. Interdiscip Perspect Infect Dis. 2010;2010:876450.

39. Bransfield RC. Lyme disease, comorbid tick-borne diseases, and neuropsychiatric disorders. Psychiatr Times. 2007;24(14): 59-62.

40. Paige RM, Beals M. Lyme disease: now playing in your area. Health Educ. 1990;21(4):4-45.

41. Sherr VT. "Bell's Palsy of the Gut" and other GI manifestations of Lyme and associated diseases. A special article. Pract Gastroenterol. 2006;30(4):74-91.

42. Kaur N, Kumar P, Malhotra S, et al. Psychomicrobiology infections, depression and suicidal behaviour. Delphi Psychiatry J. 2015;18(1): $142-150$.

43. Borgermans L, Goderis G, Vandevoorde J, Devroey D. Relevance of chronic Lyme disease to family medicine as a complex multidimensional chronic disease construct: a systematic review. Int J Family Med. 2014;2014:138016.

44. Lang D, Liegner K. Coping with Lyme Disease: A Practical Guide to Dealing with Diagnosis and Treatment. New York, NY: Henry Holt; 2004.

45. Vanderhoof-Forschner K. Everything You Need to Know About Lyme Disease and Other Tick Borne Disorders. Hoboken, NJ: John Wiley and Sons; 2004.

46. Bean CA, Fein LA. Beating Lyme Disease: Understanding and Treating This Complex and Often Misdiagnosed Disease. New York, NY: Amacom; 2008.

47. Cashel A. Suffering the Silence: Chronic Lyme Disease in an Age of Denial. Berkeley, CA: North Atlantic Books; 2016.

48. Solomon SP, Hilton E, Weinschel BS, Pollack S, Grolnick E. Psychological factors in the prediction of Lyme disease course. Arthritis Care Res. 1998;11(5):419-426.

49. LYMErix. United States of America Food and Drug Administration Center for Biologics Evaluation and Research Vaccines and Related Biological Products Advisory Committee Meeting; Bethesda, MD: January 31, 2001.

50. Kessler RC, Berglund P, Demler O, et al; National Comorbidity Survey Replication. The epidemiology of major depressive disorder: results from the National Comorbidity Survey Replication (NCS-R). JAMA. 2003;289(23):3095-3105.

51. Aucott JN, Rebman AW, Crowder LA, Kortte KB. Post-treatment Lyme disease syndrome symptomatology and the impact on life functioning: is there something here? Qual Life Res. 2013;22(1):75-84.

52. Logigian EL, Kaplan RF, Steere AC. Chronic neurologic manifestations of Lyme disease. N Engl J Med. 1990;323(21):1438-1444.

53. Shea L. Psychological Symptoms in Children with Lyme Disease. Presented at Challenges and Controversy in Lyme Disease and Tick Borne Illness Care Symposium, Massachusetts General Hospital; November 9, 2013; Boston, MA.

54. Gustaw K, Beltowska K, Studzińska MM. Neurological and psychological symptoms after the severe acute neuroborreliosis. Ann Agric Environ Med. 2001;8(1):91-94.

55. Oczko-Grzesik B, Kępa L, Puszcz-Matlińska M, Pudło R, Żurek A, Badura-Głąbik T. Estimation of cognitive and affective disorders occurrence in patients with Lyme borreliosis. Ann Agric Environ Med. 2017;24(1):33-38
56. Lobraico J, Butler A, Petrini J, Ahmadi R. New insights into stages of Lyme disease symptoms from a novel hospital-based registry. J Prim Care Community Health. 2014;5(4):284-287.

57. Johnson L, Wilcox S, Mankoff J, Stricker RB. Severity of chronic Lyme disease compared to other chronic conditions: a quality of life survey. PeerJ. 2014;2:e322.

58. Sashin D. Lyme disease and suicide an ignored problem. CNN iReport. 2013. Available from: http://ireport.cnn.com/docs/DOC-1037462. Accessed March 3, 2017.

59. Conroy C. Suicide in the workplace: incidence, victim characteristics, and external cause of death. J Occup Med. 1989;31(10):847-851.

60. Alexopoulos EC, Kavalidou K, Messolora F. Suicide mortality across broad occupational groups in Greece: a descriptive study. Saf Health Work. 2016;7(1):1-5.

61. Halpern LW. Analysis finds about 20 veterans died daily from suicide between 2001 and 2014. Am J Nurs. 2016;116(10):17.

62. Lee HE, Kim HR, Chung YK, Kang SK, Kim EA. Mortality rates by occupation in Korea: a nationwide, 13 year follow-up study. Occup Environ Med. 2016;73(5):329-335.

63. Kaplan MS, Huguet N, McFarland BH, Newsom JT. Suicide among male veterans: a prospective population-based study. J Epidemiol Community Health. 2007;61(7):619-624. Erratum in: J Epidemiol Community Health. 2007;61(8):751.

64. McIntosh WL, Spies E, Stone DM, Lokey CN, Trudeau AR, Bartholow B. Suicide rates by occupational group - 17 states, 2012. MMWR Morb Mortal Wkly Rep. 2016;65(25):641-645.

65. Stallones L, Doenges T, Dik BJ, Valley MA. Occupation and suicide: Colorado, 2004-2006. Am J Ind Med. 2013;56(11):1290-1295.

66. Zając V, Pinkas J, Wójcik-Fatla A, Dutkiewicz J, Owoc A, Bojar I. Prevalence of serological response to Borrelia burgdorferi in farmers from eastern and central Poland. Eur J Clin Microbiol Infect Dis. 2017;36(3):437-446.

67. Lyme disease risk assessment US army. Available from: http:// lymeblog.com/LDRA-USARMY83-96/lyme.htm. Accessed March 3, 2017.

68. Maes M, Berk M, Goehler L, et al. Depression and sickness behavior are Janus-faced responses to shared inflammatory pathways. BMC Med. 2012;10:66.

69. Okusaga O, Yolken RH, Langenberg P, et al. Association of seropositivity for influenza and coronaviruses with history of mood disorders and suicide attempts. $J$ Affect Disord. 2011;130(1-2):220-225.

70. Dickerson F, Wilcox HC, Adamos M, et al. Suicide attempts and markers of immune response in individuals with serious mental illness. J Psychiatr Res. 2017;87:37-43.

71. Coryell W, Yolken R, Butcher B, et al. Toxoplasmosis titers and past suicide attempts among older adolescents initiating SSRI treatment. Arch Suicide Res. 2016;20(4):605-613.

72. Sockalingam S, Links PS, Abbey SE. Suicide risk in hepatitis C and during interferon-alpha therapy: a review and clinical update. J Viral Hepat. 2011;18(3):153-160.

73. Nanni MG, Caruso R, Mitchell AJ, Meggiolaro E, Grassi L. Depression in HIV infected patients: a review. Curr Psychiatry Rep. 2015; 17(1):530.

74. Lester D. Brain parasites and suicide. Psychol Rep. 2010;107(2):424.

75. Strid JM, Christiansen CF, Olsen M, Qin P. Hospitalisation for chronic obstructive pulmonary disease and risk of suicide: a population-based case-control study. BMJ Open. 2014;4(11):e006363.

76. Lund-Sørensen H, Benros ME, Madsen T, et al. A nationwide cohort study of the association between hospitalization with infection and risk of death by suicide. JAMA Psychiatry. 2016;73(9):912-919.

77. Dunn AJ. Effects of cytokines and infections on brain neurochemistry. Clin Neurosci Res. 2006;6(1-2):52-68.

78. Chang BP, Franklin JC, Ribeiro JD, et al. Biological risk factors for suicidal behaviors: a meta-analysis. Transl Psychiatry. 2016;6(9): e887.

79. Brundin L, Erhardt S, Bryleva EY, Achtyes ED, Postolache TT. The role of inflammation in suicidal behaviour. Acta Psychiatr Scand. 2015; 132(3):192-203. 
80. Miná VA, Lacerda-Pinheiro SF, Maia LC, et al. The influence of inflammatory cytokines in physiopathology of suicidal behavior. $J$ Affect Disord. 2015;172:219-230.

81. Serafini G, Pompili M, Elena Seretti M, et al. The role of inflammatory cytokines in suicidal behavior: a systematic review. Eur Neuropsychopharmacol. 2013;23(12):1672-1686.

82. Lucaciu LA, Dumitrascu DL. Depression and suicide ideation in chronic hepatitis $\mathrm{C}$ patients untreated and treated with interferon: prevalence, prevention, and treatment. Ann Gastroenterol. 2015;28(4):440-447.

83. Westling S, Ahrén B, Träskman-Bendz L, Brundin L. Increased IL-1 $\beta$ reactivity upon a glucose challenge in patients with deliberate self-harm. Acta Psychiatr Scand. 2011;124(4):301-306.

84. Lindqvist D, Janelidze S, Hagell P, et al. Interleukin-6 is elevated in the cerebrospinal fluid of suicide attempters and related to symptom severity. Biol Psychiatry. 2009;66(3):287-292.

85. Steiner J, Bielau H, Brisch R, et al. Immunological aspects in the neurobiology of suicide: elevated microglial density in schizophrenia and depression is associated with suicide. J Psychiatr Res. 2008;42(2): 151-157.

86. Pandey GN, Rizavi HS, Ren X, et al. Proinflammatory cytokines in the prefrontal cortex of teenage suicide victims. J Psychiatr Res. 2012; 46(1):57-63.

87. O'Donovan A, Rush G, Hoatam G, et al. Suicidal ideation is associated with elevated inflammation in patients with major depressive disorder. Depress Anxiety. 2013;30(4):307-314.

88. Black C, Miller BJ. Meta-analysis of cytokines and chemokines in suicidality: distinguishing suicidal versus nonsuicidal patients. Biol Psychiatry. 2015;78(1):28-37.

89. Jablonska E, Marcinczyk M. TLR2 expression in relation to IL-6 and IL-1 $\beta$ and their natural regulators production by PMN and PBMC in patients with Lyme disease. Mediators Inflamm. 2006;2006(1): 32071.

90. Pietikäinen A, Maksimow M, Kauko T, Hurme S, Salmi M, Hytönen J. Cerebrospinal fluid cytokines in Lyme neuroborreliosis. J Neuroinflammation. 2016;13(1):273.

91. Halaris A. Panels of inflammation biomarkers, growth factors and kynurenine metabolites aid in stratification of depressed patients. Neurol Psychiatry Brain Res. 2016;22(1):12-13.

92. Brundin L, Sellgren CM, Lim CK, et al. An enzyme in the kynurenine pathway that governs vulnerability to suicidal behavior by regulating excitotoxicity and neuroinflammation. Transl Psychiatry. 2016; 6(8):e865.

93. Bay-Richter C, Linderholm KR, Lim CK, et al. A role for inflammatory metabolites as modulators of the glutamate N-methyl-D-aspartate receptor in depression and suicidality. Brain Behav Immun. 2015; 43:110-117.

94. Brundin L, Bryleva EY, Thirtamara Rajamani K. Role of inflammation in suicide: from mechanisms to treatment. Neuropsychopharmacology. 2017;42(1):271-283.

95. Steiner J, Walter M, Gos T, et al. Severe depression is associated with increased microglial quinolinic acid in subregions of the anterior cingulate gyrus: evidence for an immune-modulated glutamatergic neurotransmission? J Neuroinflammation. 2011;8:94.

96. Love AC, Schwartz I, Petzke MM. Induction of indoleamine 2,3dioxygenase by Borrelia burgdorferi in human immune cells correlates with pathogenic potential. J Leukoc Biol. 2015;97(2):379-390.

97. Halperin JJ, Heyes MP. Neuroactive kynurenines in Lyme borreliosis. Neurology. 1992;42(1):43-50.

98. Johnston JA, Wang F, Liu J, et al. Multimodal neuroimaging of frontolimbic structure and function associated with suicide attempts in adolescents and young adults with bipolar disorder. Am J Psychiatry. 2017:appiajp201615050652.
99. Mian MK, Eskandar EN. 212 A distributed network for emotional and nonemotional conflict processing. Neurosurgery. 2016;63 Suppl 1:183.

100. Davidson RJ, Putnam KM, Larson CL. Dysfunction in the neural circuitry of emotion regulation - a possible prelude to violence. Science. 2000;289(5479):591-594.

101. Lee R, Arfanakis K, Evia AM, Fanning J, Keedy S, Coccaro EF. White matter integrity reductions in intermittent explosive disorder. Neuropsychopharmacology. 2016;41(11):2697-2703.

102. Verma V, Roman M, Shah D, Zaretskaya M, Yassin MH. A case of chronic progressive Lyme encephalitis as a manifestation of late Lyme neuroborreliosis. Infect Dis Rep. 2014;6(4):5496.

103. Bransfield RC. The neuropsychiatric assessment of Lyme disease by the primary care physician. Paper presented at: 11th Annual International Scientific Conference on Lyme Disease \& Other Spirochetal and Tick-borne Disorders; April 25, 1998; New York, NY.

104. Bransfield RC. The neuropsychiatric assessment of Lyme disease. 1996. Available from: http://www.mentalhealthandillness.com/ lymeframes.html. Accessed March 3, 2017.

105. Stricker RB, Johnson L. Lyme disease diagnosis and treatment: lessons from the AIDS epidemic. Minerva Med. 2010;101(6):419-425.

106. Cook MJ, Puri BK. Application of Bayesian decision-making to laboratory testing for Lyme disease and comparison with testing for HIV. Int J Gen Med. 2017;10:113-123.

107. Elsner RA, Hastey CJ, Olsen KJ, Baumgarth N. Suppression of longlived humoral immunity following Borrelia burgdorferi infection. PLoS Pathog. 2015;11(7):e1004976.

108. Embers ME, Ramamoorthy R, Philipp MT. Survival strategies of Borrelia burgdorferi, the etiologic agent of Lyme disease. Microbes Infect. 2004;6(3):312-318.

109. Stubbs B, Wu YT, Prina AM, Leng Y, Cosco TD. A population study of the association between sleep disturbance and suicidal behaviour in people with mental illness. J Psychiatr Res. 2016;82:149-154.

110. Dersch R, Sommer H, Rauer S, Meerpohl JJ. Prevalence and spectrum of residual symptoms in Lyme neuroborreliosis after pharmacological treatment: a systematic review. J Neurol. 2016;263(1):17-24.

111. Asch ES, Bujak DI, Weiss M, Peterson MG, Weinstein A. Lyme disease: an infectious and postinfectious syndrome. J Rheumatol. 1994;21(3):454-461.

112. Johnson L, Aylward A, Stricker RB. Healthcare access and burden of care for patients with Lyme disease: a large United States survey. Health Policy. 2011;102(1):64-71.

113. Mueller TI, Leon AC, Keller MB, et al. Recurrence after recovery from major depressive disorder during 15 years of observational follow-up. Am J Psychiatry. 1999;156(7):1000-1006.

114. Fallon BA, Coyle P, Liegner K, Nields J, Rissenberg M, Bransfield RC. Neuropsychiatric Lyme Disease Symposium at 149th Annual Meeting of American Psychiatric Association; New York, NY. May 9, 1996.

115. Hassett AL, Radvanski DC, Buyske S, et al. Role of psychiatric comorbidity in chronic Lyme disease. Arthritis Rheum. 2008;59(12): 1742-1749.

116. Tager FA, Fallon BA, Keilp J, Rissenberg M, Jones CR, Liebowitz MR. A controlled study of cognitive deficits in children with chronic Lyme disease. J Neuropsychiatry Clin Neurosci. 2001;13(4):500-507.

117. Fallon BA. Paper presented at: Challenges and Controversy in Lyme Disease and Tick Borne Illness Care Symposium; November 9, 2013; Boston, MA. 


\section{Publish your work in this journal}

Neuropsychiatric Disease and Treatment is an international, peerreviewed journal of clinical therapeutics and pharmacology focusing on concise rapid reporting of clinical or pre-clinical studies on a range of neuropsychiatric and neurological disorders. This journal is indexed on PubMed Central, the 'PsycINFO' database and CAS, and is the official journal of The International Neuropsychiatric Association (INA). The manuscript management system is completely online and includes a very quick and fair peer-review system, which is all easy to use. Visit http://www.dovepress.com/testimonials.php to read real quotes from published authors.

\footnotetext{
Submit your manuscript here: http://www.dovepress.com/neuropsychiatric-disease-and-treatment-journal
} 